\title{
Raised serum hCG in a male patient caused by primary jejunal choriocarcinoma
}

\author{
G S W Chan, W K Ng, D T T Chua, P C Wu
}

\begin{abstract}
A rare case of primary choriocarcinoma of the jejunum occurred in a 45 year old Chinese man. This tumour was associated with massive melaena and a markedly raised serum human chorionic gonadotrophin ( $\beta$-hCG) concentration. Necropsy examination showed no primary lesion in other possible sites including testes, mediastinum, and pineal gland. Histologically, the tumour showed morphology typical of choriocarcinoma with no adenocarcinomatous element identified. The presence of choriocarcinoma in non-gonadal sites may be explained by retrodifferentiation or metaplasia of a conventional carcinomatous component to primitive trophoblasts. Serum $\beta$-hCG level may represent a useful marker in earlier diagnosis and monitoring of this potentially treatable disease.

(F Clin Pathol 1998;51:413-415)
\end{abstract}

Keywords: choriocarcinoma; jejunum; hCG

Human chorionic gonadotrophin (hCG) is normally secreted by syncytiotrophoblastic cells during pregnancy. Early in the first trimester it maintains the integrity of corpus luteum; this secretes sufficient progesterone to preserve the secretory endometrium which is mandatory for the development of the embryo. An increase of serum hCG concentration in a male patient often suggests malignant neoplasms with a trophoblastic element. Common examples include classic seminoma with syncytiotrophoblast-like giant cells, combined germ cell tumour, and choriocarcinoma. Production of hCG is also occasionally noted in non-choriocarcinomatous carcinoma of liver, lung, and colon. ${ }^{12}$

Non-gestational choriocarcinomas typically arise from gonadal organs. They may, however, originate in extragenital sites such as the mediastinum, retroperitoneum, pineal gland, liver, gallbladder, and urinary tract. ${ }^{3-5}$ Primary choriocarcinoma in the gastrointestinal tract is rare and has been most often reported in the stomach. ${ }^{67}$ So far only three cases of primary choriocarcinoma of the small intestine have been reported in English language journals. ${ }^{8-10}$ We report the fourth case of primary choriocarcinoma arising in the jejunum of a male patient. The tumour was associated with markedly raised serum hCG concentration, which is important in diagnosis and in monitoring clinical progress. We also explore current theories about the pathogenesis of the extragonadal choriocarcinoma.

\section{Case report}

A 45 year old Chinese man presented with recurrent melaena of several weeks' duration. On admission, his haemoglobin concentration was $10.4 \mathrm{~g} / \mathrm{dl}$ and fell to $5.6 \mathrm{~g} / \mathrm{dl}$ five hours afterwards, following massive fresh melaena. Emergency upper endoscopy showed mild gastritis and no active bleeding site was identified. Colonoscopy was performed and suggested that the source of bleeding was above the caecum. A small mesenteric arteriogram with both arterial and venous phases revealed dense contrast staining in the proximal jejunum, suggesting a vascular tumour there. Chest $x$ ray showed multiple nodular opacities over both lung fields. Hepatic and renal functions were only mildly impaired. As the patient continued to develop recurrent melaena, laparotomy was performed to resect the tumour.

There were multiple haemorrhagic and necrotic tumour masses in the small intestinal wall. The largest was found in the jejunum and measured $9 \mathrm{~cm}$ in its greatest dimension. Smaller satellite tumour nodules were also identified, with mucosal ulceration and full thickness infiltration to the serosa. Multiple metastatic tumour masses were also seen in the liver. A segment of small intestine measuring $50 \mathrm{~cm}$ in length was resected. Multiple tissue blocks were sampled from the jejunal tumour, promptly fixed in $10 \%$ neutral buffered formalin, and embedded in paraffin wax. Sections 3 $\mu \mathrm{m}$ thick were cut and stained with haematoxylin and eosin, mucicarmine, periodic acidSchiff (PAS) with and without diastase digestion, and alcian blue. Immunohistochemical studies were performed on the paraffin sections using the streptavidin-biotin complex method with antibodies directed against Mak 6 (Zymed, San Francisco, California, USA), cytokeratin 7 (Dako, Carpinteria, California, USA), cytokeratin 20 (Dako), hCG (Dako), human placental lactogen (Dako), placental alkaline phosphatase (Zymed), epithelial membrane antigen (Dako), carcinoembryonic antigen (monoclonal, Zymed), BerEP4 (Dako), LeuM1 (CD15, Becton Dickinson, San Jose, California, USA), BerH2 (CD30, Dako), vimentin (Dako), S-100 protein (Dako), and $\alpha$-fetoprotein (Dako).

Microscopically, there was transmural infiltration of the jejunal wall by sheets of tumour cells with prominent areas of haemorrhage and necrosis. The tumour was composed of biphasic populations of cells arranged in a plexiform pattern. There were aggregates of polygonal mononuclear cells with vesicular nuclei, ample pale to amphophilic cytoplasm, and well defined cell borders. These cells were focally 


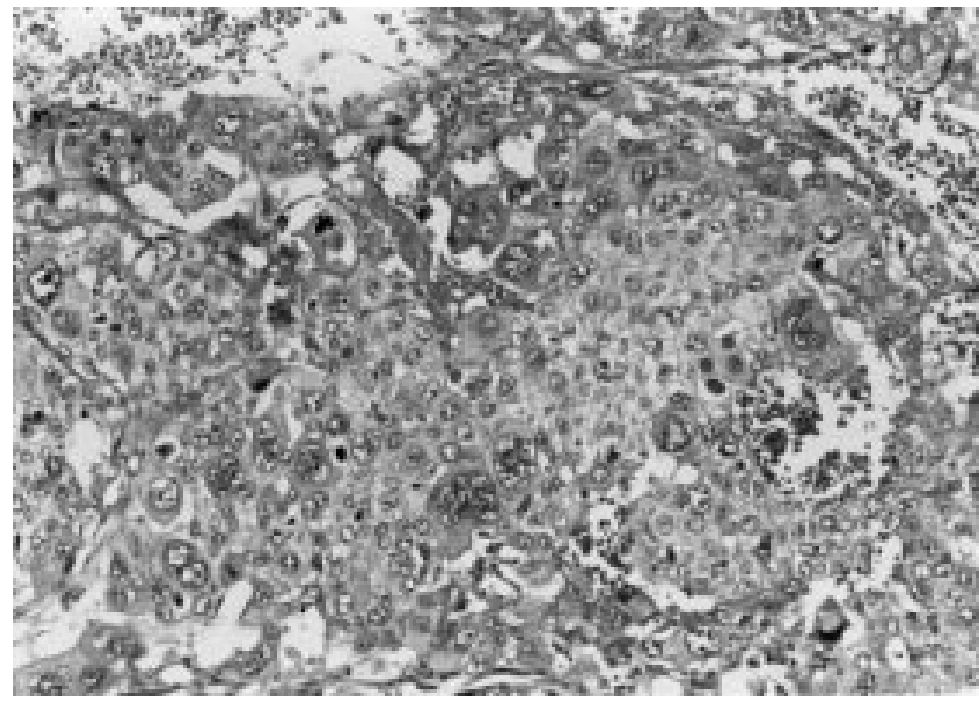

Figure 1 Photomicrograph of the jejunal tumour showing mononuclear malignant cytotrophoblasts capped by multinucleated syncytiotrophoblasts (haematoxylin and eosin, $\times 248$ ).

capped by multinucleated syncytial cells with smudged nuclei, eosinophilic cytoplasm, and irregular cytoplasmic margins (fig 1). Lymphovascular permeation was frequently seen with regional lymph node metastases. No associated adenocarcinomatous component was present. The tumour cells were mucin negative. On immunohistochemistry, they were positive for cytokeratin markers Mak 6 and cytokeratin 7. The syncytiotrophoblasts were highlighted by hCG and human placental lactogen, while the cytotrophoblasts were only focally and weakly positive for the latter (fig 2). There were also focal stainings for epithelial membrane antigen. The tumour cells were negative for cytokeratin 20, placental alkaline phosphatase, carcinoembryonic antigen, BerEP4, LeuM1, BerH2, vimentin, S-100 protein and $\alpha$-fetoprotein. In view of the histopathological features, circulating $\beta$-hCG concentration was subsequently assayed. It was found to be greatly raised to the level of $110,140 \mathrm{IU} / 1$ (nor$\mathrm{mal}=0-5 \mathrm{IU} / \mathrm{l})$. Serum $\alpha$-fetoprotein and carcinoembryonic antigen levels were within nor-

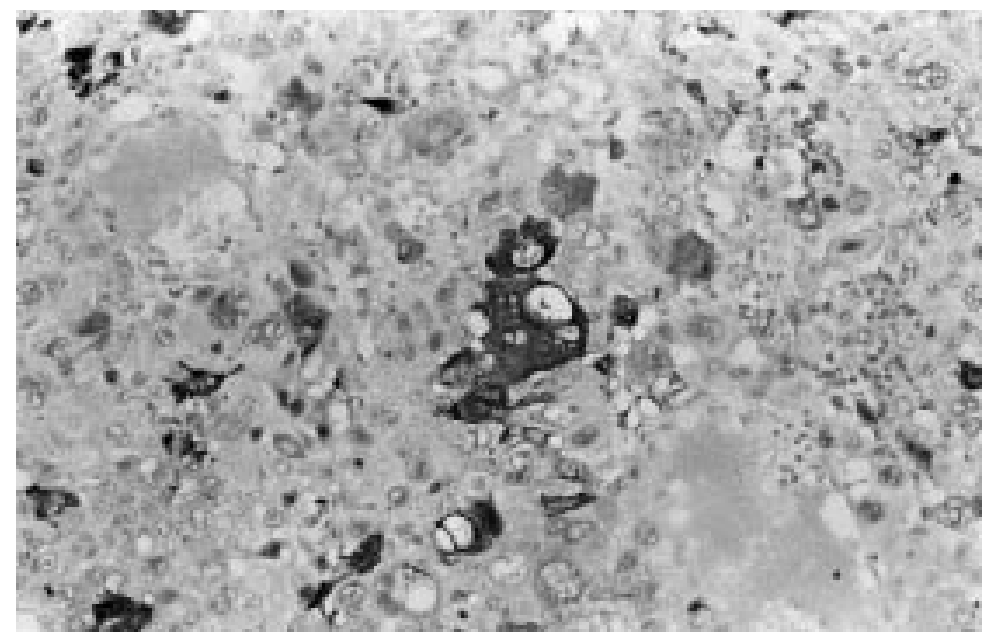

Figure 2 Photomicrograph of immunohistochemical staining showing strong cytoplasmic positivity for hCG in the malignant syncytiotrophoblasts. The mononuclear cytotrophoblasts fail to express the antigen. $(\times 248)$. mal limits. Ultrasonography of both testes revealed no abnormality.

The patient was given multiagent chemotherapy (bleomycin, etoposide, and cisplatinum) for three days. This was eventually withdrawn, however, owing to the development of pancytopenia. The patient ran a rapid deteriorating course and died two months after admission. A clinical necropsy was performed to document the primary origin of the choriocarcinoma. There were multiple metastatic tumour nodules, ranged from several millimetres to $3 \mathrm{~cm}$ in greatest dimension, present in the lungs, liver, and omentum. They appeared haemorrhagic and necrotic and it was confirmed that they had similar histological features to the jejunal tumour. Both testes were serially sectioned and all embedded for microscopic examination. They showed no significant pathology with no fibrosis, necrosis, or calcification identified. Other sites including the anterior mediastinum, retroperitoneum, urinary bladder, and pineal gland were also examined and appeared unremarkable.

\section{Discussion}

Extragenital choriocarcinoma in the gastrointestinal tract is rare and most frequently occurs in the stomach. ${ }^{67}$ Only eight cases of small intestinal choriocarcinoma have been reported in English language journals, ${ }^{8-15}$ five of them being metastatic from other sites. The remaining three were believed to be primary, originating in duodenum or jejunum. ${ }^{8-10}$ The diagnosis of primary gastrointestinal choriocarcinoma is based on normalisation of the serum $\beta$-hCG concentration after resection of the bowel tumour or exclusion of other possible primary sites, which unfortunately often requires necropsy. In male patients, testicular choriocarcinoma may regress, leaving only foci of fibrosis and calcification. ${ }^{12}{ }^{16}$ Thorough examination of the testes is thus mandatory before a diagnosis of primary extragenital choriocarcinoma is made. The serum $\beta$-hCG concentration in this patient, which remained high even after resection of the jejunal tumour, could be explained by the widely disseminated disease.

The pathogenesis of extragenital choriocarcinoma in male patients remains obscure and speculative. Some have postulated that misplaced multipotential cells of the blastula or morula stages of embryogenesis give rise to this tumour in later life. ${ }^{17}$ On the other hand, the "embryonic rest" theory states that parietal germ cell nests may fail in their normal migration from the urogenital ridges to the site of the adult gonads. They then become displaced in the abdomen and eventually turn neoplastic. ${ }^{18}$ This explanation is especially useful for choriocarcinoma in the retroperitoneum or urinary bladder. Choriocarcinoma in the small intestine may also represent metastatic foci of a primary gonadal tumour which has regressed. ${ }^{12} 16$ For primary intestinal choriocarcinoma, the most popular theory, however, is that of retrodifferentiation or metaplasia of adenocarcinoma cells to embryonal trophoblasts. This theory is supported by the frequent occurrence 
of both adenocarcinomatous and choriocarcinomatous elements in gastric and colonic choriocarcinoma. $^{7}{ }^{10}$ 19-22 In those tumours with choriocarcinoma as the sole component, the adenocarcinomatous element may have been completely effaced by the more aggressive choriocarcinomatous overgrowth. Alternatively, complete metaplasia to choriocarcinoma with no residual adenocarcinoma is also suggested. In our case, no adenocarcinomatous component was identified. Immunohistochemically, this tumour failed to express cytokeratin 20, which is commonly positive in the conventional intestinal carcinoma. The absence of "intestinal" cytokeratin can be explained by complete retrodifferentiation or metaplasia with total loss of the original cytokeratin profile. This postulation is further supported by the negativity for carcinoembryonic antigen.

Trophoblastic tumours, as in this case, are often accompanied by a markedly increased serum $\beta$-hCG concentration. Detection of serum hCG in non-pregnant patients, however, does not necessarily mean the presence of trophoblastic neoplasms. Occasionally, ectopic $\beta$-hCG production may be seen in nontrophoblastic non-endocrine neoplasms in various organs. Commoner examples include gastric and colonic adenocarcinoma, bronchogenic carcinoma, hepatocellular carcinoma, breast carcinoma, and melanoma. ${ }^{1}$ These are associated with at most a modest rise in circulating hCG concentration ${ }^{1}$ compared with trophoblastic tumours.

Although extragenital choriocarcinoma is rare and is known for its extremely poor prognosis, recent advances in the treatment of choriocarcinoma with chemotherapeutic agents have made it a potentially treatable disease. Earlier diagnosis may offer a better chance of survival. Measurement of serum $\beta$-hCG concentration may be helpful in the investigation of hypervascular tumours in the gastrointestinal tract, as choriocarcinoma, though rare, always features in the differential diagnosis. The main use of the associated hCG secretion, however, lies in the monitoring of treatment response and disease progress. Analysis of follow up serum hCG concentrations can be useful for assessing any possible residual disease or tumour recurrence.

1 Gailani S, Chu TM, Nussbaum A, et al. Human chorionic gonadotrophins (hCG) in non-trophoblastic neoplasms. Assessment of abnormalities of hCG and CEA in bronchogenic and digestive neoplasms. Cancer 1976;38:1684-6.

2 Aru A, Rasmussen LA, Federspiel B, et al. Glassy cell carcinoma of the colon with human chorionic gonadotrophin production: a case report with immunohistochemical and ultrastructural analysis. Am f Surg Pathol 1996;20:187-92.

3 Fine G, Smith RW, Pachter MR. Primary extragenital choriocarcinoma in the male subject. Am $\mathcal{F}$ Med 1962;32:77694.

4 Kawamura J, Rhinsho K, Taki Y, et al. Choriocarcinoma and undifferentiated cell carcinoma of the bladder with gonadotrophin secretion. F Urol 1979;121:684-6.

5 Abu-Farsakh H, Fraire AE. Adenocarcinoma and (extragonadal) choriocarcinoma of the gallbladder in a young noman. Hum Pathol 1991;22:614-15.

6 Smith FR, Barkin JS, Hensley G. Choriocarcinoma of the stomach. Am f Gastroenterol 1980;73:45-8.

7 Saigo VE, Brigati DJ, Sternberg SS, et al. Primary gastric choriocarcinoma: an immunohistological study. Am $\mathcal{F}$ Surg Pathol 1981;5:333-42.

8 Soresi AL. Chorioepithelioma of the jejunum. Am $\mathcal{f}$ Cancer 1936;28:583-6.

9 Matthews TH, Heaton GE, Christopherson WM. Primary duodenal choriocarcinoma. Arch Pathol Lab Med 1986;110: $550-2$.

10 Harada N, Misawa T, Chijiiwa Y, et al. A case of extragenital choriocarcinoma in the jejunum. Am f Gastroenterol 1991; 86:1077-9.

11 Sears JB. Ectopic chorioepithelioma: report of case in which the lesion was situated in the jejunum. Ann Surg 1933;97:910-19.

12 Engel JM, Deitch EA, Risch J. Extragenital choriocarcinoma in the duodenum. Am $\mathcal{F}$ Roentgenol 1979;133:933-5.

13 Suski E, Pavlides C, Matsumoto T. Massive lower gastrointestinal bleeding: unusual presentation of metastatic choriocarcinoma. Int Surg 1979;64:53-5

14 Meryn S, Potzi R, Graninger W, et al. Endoscopic removal of choriocarcinoma metastasis in a patient with chronic intestinal hemorrhage. Endoscopy 1983;15:34-5.

15 Kristoffersson A, Emdin S, Jarhult J. Acute intestinal obstruction and splenic hemorrhage due to metastatic choriocarcinoma. A case report. Acta Chir Scand 1985;151: 381-4.

16 Azzopardi JG, Mostofi FK, Theiss EA. Lesions of the testes observed in certain patients with widespread choriocarcinoma and related tumours: the significance and genesis of hematoxylin-staining bodies in the human testis. Am $\mathcal{f}$ Pathol 1961;38:207-25.

17 Schlumberger HG. Teratoma of the anterior mediastinum in the group of military age: a study of 16 cases, and a review of theories of genesis. Arch Pathol 1946;41:398-444.

18 Witschi E. Migration of the germ cells of human embryos from the yolk sac to the primitive gonadal folds. Carnegie Institute of Washington Contributions to Embryology 1948;32: $67-80$.

19 McKechnie JC, Fechner RE. Choriocarcinoma and adenocarcinoma of the esophagus with gonadotrophin secretion. Cancer 1971;27:694-702.

20 Maher JG, Donohoe JF, Fennelly JJ, et al. Extragenital choriocarcinoma in a female presenting as a gastric tumour. $\mathrm{Br}$ f Surg 1970;57:73-5.

21 Ordonez NG, Luna MA. Choriocarcinoma of the colon. $A m$ f Gastroenterol 1984;79:39-42.

22 Kubosawa H, Nagao K, Kondo Y, et al. Coexistence of adenocarcinoma and choriocarcinoma in the sigmoid colon. Cancer 1984;54:866-8. 